\title{
Investigation of Wear Behaviour of Al6061 reinforcement with TiC and $\mathrm{MoS}_{2}$
}

\author{
S.Rajesh ${ }^{1, a}$, C. Velmurugan ${ }^{2, b}$ \\ ${ }^{1}$ Assistant professor, Department of Mechanical Engineering, Kumaraguru College of technology, Coimbatore, \\ India-641049 \\ ${ }^{2}$ professor, Department of Mechanical Engineering, Kumaraguru College of technology, Coimbatore, India- \\ india-641049 \\ a rajesh.mech512@gmail.com, ${ }^{\mathrm{b}} \mathrm{C} \_$velmurugan16@yahoo.co.in
}

\begin{abstract}
Metal matrix composite (MMC) focuses primarily on improved specific strength, high temperature and wear resistance application. Aluminum matrix reinforced with titanium carbide and molybdenum disulfide has good potential and also selflubrication. The main challenge is to produce this composite in a cost effective way to meet the above requirements. In this study Al-TiC-MoS2 castings with different volume fraction of TiC and MoS2 were produced in an argon atmosphere by an enhanced stir casting method. Hardness of the composite has increased with higher \% of TiC addition. At that same time self-lubrication of composite has occur in the effort of MoS2. Dry sliding wear behavior of AMC was analyses with the help of a pin on disc wear and friction monitor. The present analyses reveal the improved hardness as well as wear resistance.
\end{abstract}

Keywords Aluminium matrix composites, Wear, TiC, $\mathrm{MoS}_{2}$

\section{Introduction}

Among several AMC fabrication techniques, stir casting is the most conventional and economical way. Several parameters such as type volume fraction of metal, size, wettability, interfacial reactions have to be considered during fabrication of composites (8) revealed that Al-TiCp castings with different volume fraction of TiC were manufactured in an argon atmosphere by an enhanced stir casting method. (1) reported that the Synthesis and tribological characterization of Al$\mathrm{TiCp}$ composite produced by in situ process revealed that the volume fraction of TiC increased from $7 \%$ to $18 \%$ the wear rate decreased linearly. (3)investigated the tribological investigation of titanium-based materials for brakes. When considering weight of conventional cast iron rotor with the same dimensions of the titanium alloy rotor offers $37 \%$ less weigh approximately, TiC alloy offering high-temperature strength and better corrosion resistance from road-deicing salts. The thermally spray-coated Ti disc showed the least wear and merits further attention as a lightweight, corrosion-resistant brake rotor material. (7) observed that thermally sprayed molybdenum coating used as many practical applications because of excellent behavior of wear resistance coatings act in it. This paper reports a significant of spraying distance in wear resistance of molybdenum coating. It shows the influence of test configuration and conditions on the wear performance ranking of molybdenum coatings. Dhanasekaran and Gnanamoorthy (5) revealed that the abrasive wear behavior of sintered steels prepared with MoS2 addition. In this study Abrasive wear tests were carried out by sliding against the Sic abrasive sheet at room temperature. The result clearly shows that addition of $\mathrm{MoS}_{2}$ materials had a high coefficient of friction and good wear resistance exhibited a contrasted with the base synthesis compressive strength, hardness and density are influenced by the addition of $\mathrm{MoS}_{2}$.

\section{Experimental Details}

\subsection{Materials Used}

Al6061 were selected for present investigation based on Al-Cu- Mg alloy system, designated by the American Aluminium Association. This matrix was chosen since it provides excellent combination of strength and damage tolerance at higher temperatures.table 1 shows the Chemical Composition of Al6061(weight\%).

Table.1. Chemical Composition of Al6061(weight\%)

\begin{tabular}{|c|c|c|c|c|c|c|c|c|c|}
\hline Element & $\mathrm{Cr}$ & $\mathrm{Cu}$ & $\mathrm{Fe}$ & $\mathrm{Mg}$ & $\mathrm{Mn}$ & $\mathrm{Si}$ & $\mathrm{Ti}$ & $\mathrm{Zn}$ & $\mathrm{Al}$ \\
& 0.003 & 0.24 & 0.16 & 0.89 & 0.48 & 0.63 & 0.014 & 0.007 & 97.57 \\
\hline
\end{tabular}




\subsection{Stir Casting Setup}

Composite specimens consist of Al6061 alloy, tungsten carbide particles with MoS2 were fabricated using stir casting techniques. At first matrix materials was melted to superheating temperature of $790^{\circ} \mathrm{C}$ in a crucible which is made of graphite placed inside the electric induction furnace. The graphite mixer placed into a crucible when melt temperature reached $800^{\circ} \mathrm{C}$ the mixer was started to stir the molten metal at $600 \mathrm{rev} / \mathrm{min}$ for about 15 minutes The reinforcement particles were added to the molten Al 6061 alloy, to increase the wettability of composites $1 \%$ of Magnesium powder were added.

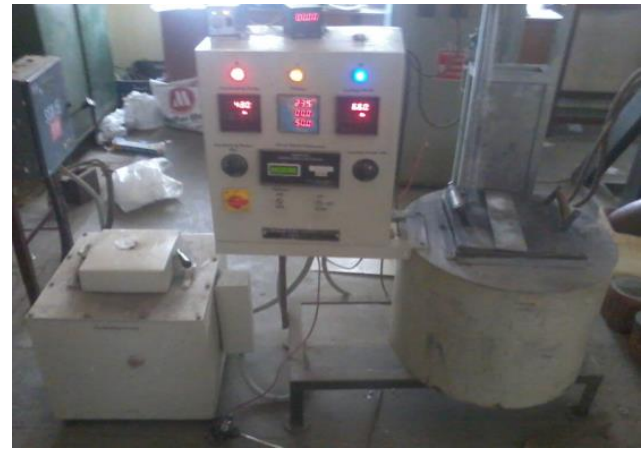

Fig.2. Stir casting Setup

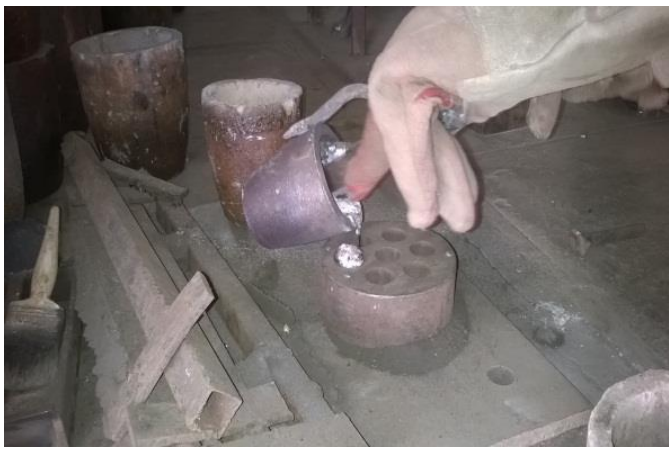

Fig.3. Mould setup

\subsection{Pin-On-Disc Apparatus}

The disk material is EN32 steel having a hardness value of HRC65. Wear test specimen were machined from cast composites to obtain cylindrical pins having a diameter of $10 \mathrm{~mm}$ and height $20 \mathrm{~mm}$, which are metallographically polished, their weights being $8.3250 \pm 0.2 \mathrm{~g}$. The wear tests were carried out at room temperature $\left(30 \pm 3 \_\mathrm{C}, \mathrm{RH} 55 \pm 5 \%\right)$ under dry sliding condition in accordance with the ASTM G 99-95 standard. Before the test, all the contacting surfaces were polished, cleaned in acetone, and dried. The wear losses of the specimens were measured using an electronic balance of $0.0001 \mathrm{~g}$ precision. The sliding distance was fixed as $3000 \mathrm{~m}$. Before and after wear testing, samples were cleaned with acetone to remove wear debris.

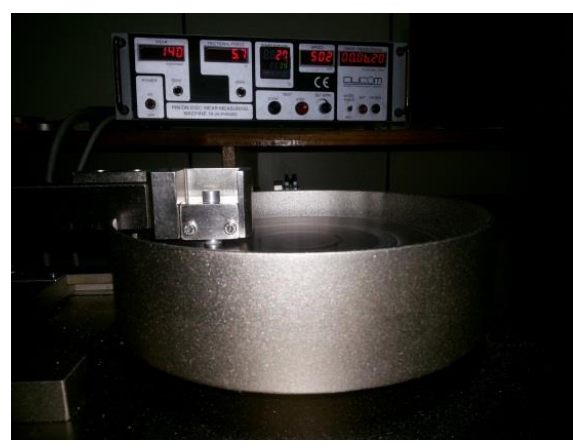

Fig.4. pin disc on apparatus

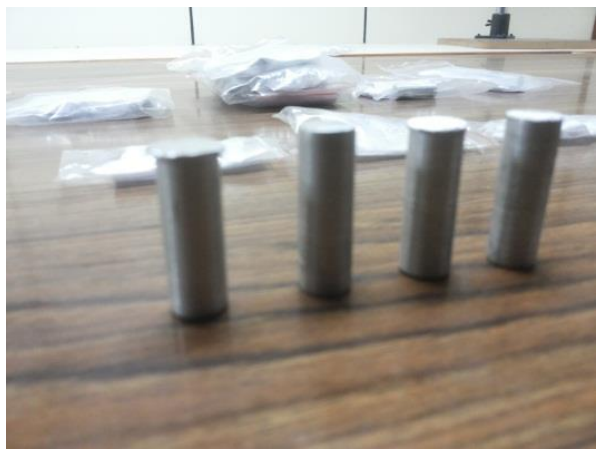

Fig.5. Wear Specimen

\section{Analysis Of Variance For Weight Loss}

The value of $\mathrm{R}^{2}$ (adjusted) is over $92.2 \%$, which means that the regression model provides an excellent explanation of the relationship between the factors and the response (weight loss). The associated $\mathrm{P}$ value for the model which is lower than 0.05 (i.e., $P=0.05$, or $95 \%$ confidence) indicates that the model is considered to be statistically significant. The ANOVA table for the quadratic model for weight loss is shown in Table 2. 
Table.2. Analysis of variances for weight loss

\begin{tabular}{|l|l|l|l|l|l|}
\hline $\begin{array}{l}\text { Source of } \\
\text { Variation }\end{array}$ & $\begin{array}{l}\text { Degree of } \\
\text { freedom }\end{array}$ & $\begin{array}{l}\text { Sum } \\
\text { squares }\end{array}$ & $\begin{array}{l}\text { Mean sum of } \\
\text { squares }\end{array}$ & F value & P value \\
\hline Regression & 7 & 0.000561 & 0.000080 & 51.74 & 0.000 \\
\hline Linear & 4 & 0.000530 & 0.000133 & 85.63 & 0.000 \\
\hline Interaction & 3 & 0.000030 & 0.000010 & 6.56 & 0.002 \\
\hline Lack of fit & 17 & 0.000027 & 0.000002 & 1.15 & \\
\hline Error & 6 & 0.000008 & 0.000001 & & \\
\hline Total & 30 & 0.000597 & & & \\
\hline
\end{tabular}

\section{Results And Discussions}

\subsection{Pin On Disc Results}

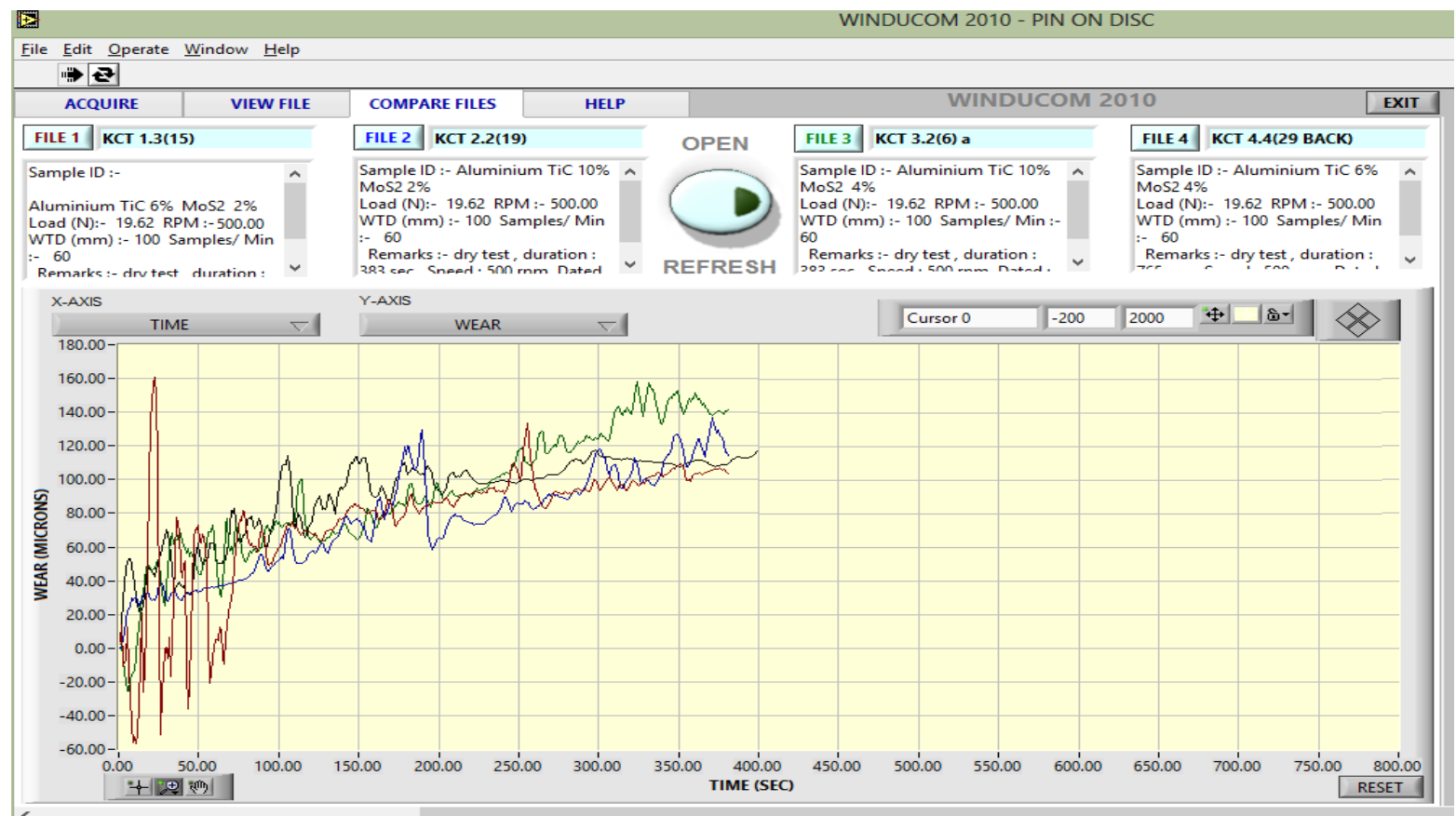

Fig.6. Wear comparison of TiC, MoS2, Load and sliding distance with different combinations.

Pin on disc result shows that when percentage of $\mathrm{TiC}, \mathrm{MoS}_{2}$ increase the weight loss of the composite materials decresase and when the load and sliding distance increase the weight loss of the composite increses. Presence of MoS $\mathrm{S}_{2} \mathrm{material}$ act as a selflubricant and the materailshardnhess increses by presences of TiC as a reinforcement in the materials. Fig $6 \mathrm{X}$ axis respect to time and $Y$ axis respect to wear. The wear was calculated every 50 second and also the wear was changed due to combination of reinforcement. Here the reinforcement of TiC and $\mathrm{MoS}_{2}$ present in $\mathrm{Al} 6061$ the wear will be reduced with the factors of sliding distance and load. 
Contour plot was drawn between sliding distances, load, $\mathrm{TiC}, \mathrm{MoS}_{2}$ particles. It was observed from figure 7 increasing the applied load and sliding distance the weight loss increasing and clearly shows that by increasing TiC, MoS 2 particles as reinforcement the weight loss of composite decreases. similiar results were observed in Velmurugan, C., Subramanian, et al.(11) "Experimental study on the effect of $\mathrm{SiC}$ and graphite particles on weight loss of $\mathrm{Al} 6061$ hybrid composite materials.

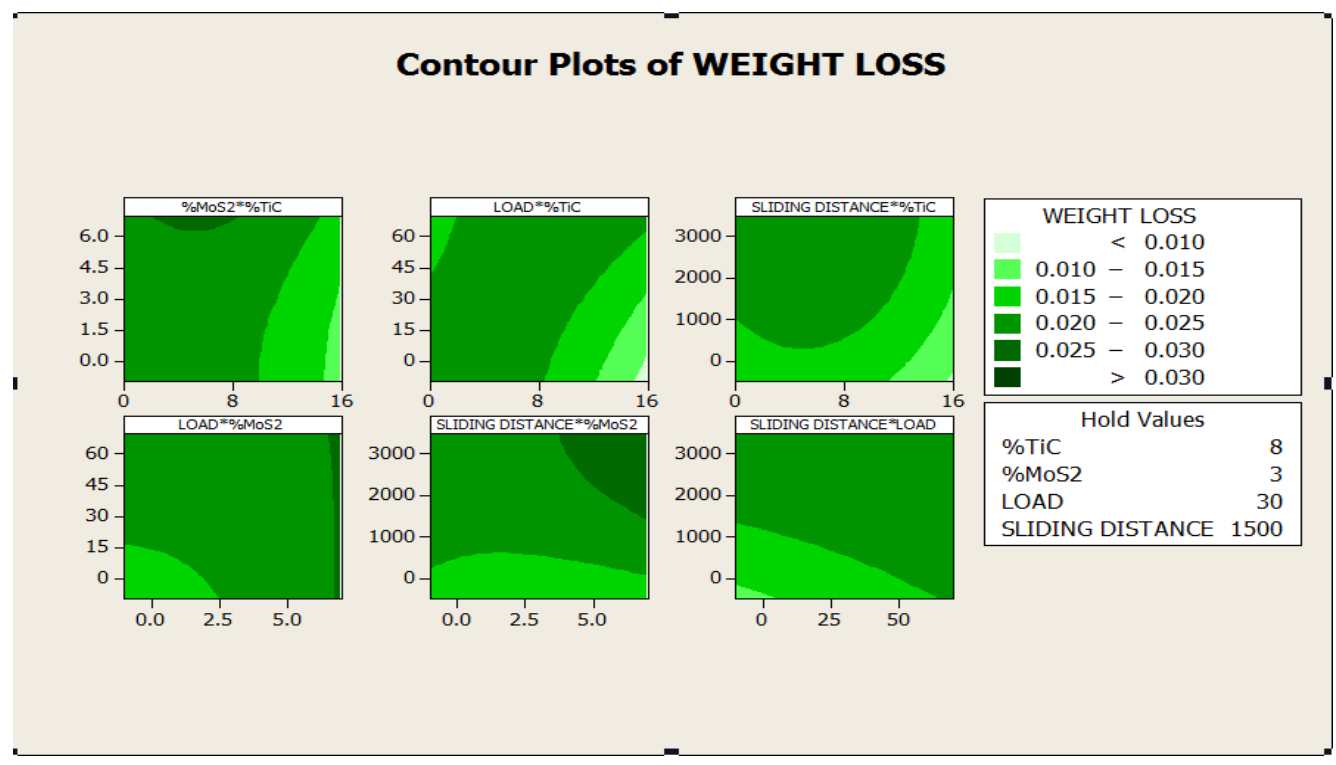

Fig.7. Counter plots of weight loss due to factor of tic, mos2, applying load and sliding disc

\section{Conclusion}

Aluminium hybrid composites containing $\mathrm{TiC}$ and $\mathrm{MoS}_{2}$ particles were fabricated using stir casting process. Wear tests were performed on specimens having the parameters of wt.\% of $\mathrm{TiC}$, wt.\% of $\mathrm{MoS}_{2}$, applied load and sliding distance were studied. The conclusions derived from this study are as follows

- The main and the interaction effects of significant combination of influencing factors within the range of investigation of $\mathrm{Al}$ alloy-TiC-MoS 2 composites were studied by central composite rotatable design technique

- The developed mathematical model can be used to predict the weight loss in terms of the influencing factors obtained from any combination within the ranges studied.

- The developed mathematical model can further be employed for optimization of the influencing factors with respect to weight loss.

- Weight loss of composite decreases with rise in weight percentage of $\mathrm{TiC}$ and $\mathrm{MoS}_{2}$ particles and increases with rise in applied load and sliding distance.

\section{References}

1. Abhishek Kumar, Rakesh, K. "Dry sliding wear of in-situ synthesized Al-TiC composites" 2015, Proceedings of Malaysian International Tribology Conference, pp. 100-101.

2. Ashok Kumar Srivastava, Karabi Das, "The abrasive wear resistance of TIC and (Ti, W) C-reinforced Fe-17Mn austenitic steel matrix Composites", Tribology International, (2010), vol. 43, pp. 944-950.

3. Basavarajappa, S. Chandramohan, G. et al. "Influence of sliding speed on the dry sliding wear behaviour and the subsurface deformation on hybrid metal matrix composite", Wear, (2007), vol. 262, pp.1007-1012.

4. Velmurugan, C., Subramanian, R., Thirugnanam, S. Anandavel, B. "Investigation of friction and wear behavior of hybrid aluminium composites", Industrial Lubrication and Tribology, (2012),Vol. 64 pp. 152 - 163 
5. Dhanasekaran, S. Gnanamoorthy, R. "Abrasive wear behavior of sintered steels prepared with MoS2addition" (2007), Wear, vol. 262, pp. 617-623.

6. Dharmalingam. S., Subramanian, R., Somasundara Vinoth, K. and Anandavel, B, "Optimization of tribological properties in aluminum hybrid metal matrix composites using gray -taguchi method". Journal of Materials Engineering and Performance,(2011) vol. 20, pp.1457-1466

7. Falcon-Franco, L. and Bedolla-Becerril, E. "Wear performance of TiC as reinforcement of a Magnesium alloy matrix composite". Composites: Part B, 2011, vol. 42, pp. 275-279.

8. Gopalakrishnan, S. Murugan, N. "Production and wear characterization of AA 6061 matrix Titanium carbide particulate reinforced composite by enhanced stir casting method", Composites: Part B, 2012, vol.43, pp.302308.

9. Jerome, S., Ravisankar, B, et al.,"Synthesis and evaluation of mechanical and high temperature tribological properties of in-situ Al-TiC composites", Tribology International, 2010, vol. 43, pp. 2029-2036.

10. Kannan, T. Murugan, N. 'Effect of flux cored arc welding process parameters on duplex stainless steel clad quality', Journal of Materials Processing Technology 2006, 176,230-239

11. Velmurugan, C., Subramanian, R. et al. "Experimental study on the effect of SiC and graphite particles on weight loss of Al 6061 hybrid composite materials", Journal of Tribology and Surface Engineering, 2011, vol. 2, pp.4968.

12. Velmurugan, C., Subramanian, R., Thirugnanam, S., Ramakrishnan, S. S., Anandavel, B., Athiyannan, S. and Dasanapu Purusotham, "Experimental studies on the wear behavior of heat treated Al 6061 hybrid metal matrix composites", International Conference on Frontiers in Automobile and Mechanical Engineering (Fame-2010), held at Sathyabama University, 25to27-10-2010

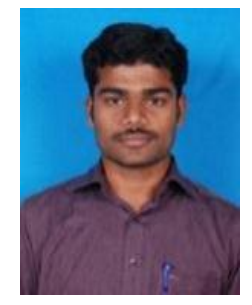

\section{Author's. biography with Photo}

Rajesh is a Assistant Professor in the Department of Mechanical Engineering at Kumaraguru College of Technology, Coimbatore. He completed his BE (Mechanical Engineering) and ME (production Engineering) First class. He is doing $\mathrm{PhD}$ work in the area of Metal Matrix Composites at Kumaraguru College of Technology under Anna University, Chennai and his main interest field is wear property study and improvement in composite materials. S.Rajesh is the corresponding author and can be contacted at: rajesh.mech512@gmail.com 